Bull. Fac. Agric., Cairo Univ., 67: 123-140(2016).

\title{
THE IMPACT OF GROWTH OF FIXED ASSETS AND ADOPTION OF TECHNOLOGY ON THE AGRICULTURAL PRODUCTION
}

(Received: 23.3.2016)

\author{
By \\ J. A. Al-Dala'een \\ Agricultural Economics, Karak University College, Balqa Applied University, Jordon
}

\begin{abstract}
The objective of this article was to investigate the changes on the economics of agricultural sector in Jordan depending on agricultural censuses. The article explains the dynamicity of agriculture production and its economics. The analysis revealed that the agricultural sector witnesses strong changes through 10 years period. The lack of agricultural national strategic plans may have caused these high variations.
\end{abstract}

Key words: agricultural productions, assets, regional distribution.

\section{INTRODUCTION}

Agriculture sector is considered a major contributor in economic growth. The contribution of agriculture besides its direct contribution to the economic growth, affects the other economic sectors directly or indirectly (Pinstrup-Andersen and Shimokawa 2006). The agricultural sector contributes in the alleviation of poverty and improving food security (Byerlee et al., 2008).

The basic purpose of planning for agricultural development is to increase productivity and production of crops and livestock, increasing the income for improving living standard of farmers and also optimum utilization of limited resources such as land, water, fertilizers and labor etc. Agricultural fixed assets play an important role in the rapid transformation of the Jordanian agriculture from traditional low productivity subsistence agriculture to modern, high productivity and commercialized agriculture, particularly, intensive irrigated agriculture (Dethier and Effenberger, 2011).

The growth of fixed assets has led to the adoption of new agricultural technology using improved and high yielding variety of seeds, improved agricultural implements, irrigation, fertilizers and plant protection chemicals etc. This, in turn, has given rise to environmental issues, which have some implications for medium and long term development of agriculture as well as life in general (Byerlee et al., 2005).
However, there are several factors affecting the rate of technology adoption. For example, land tenure and size of holdings limit the progress of technology. Farm size, the number of parcels and patterns of ownership are the most important factors in understanding farmers' behavior toward new technologies. Patterns of ownership, leasing, tenancy of land holding, and sharecropping are among the factors that affect farming practice and farmers' decision, particularly decisions to adopt new technologies. Farming systems, farm resources and farmer's characteristics including personal and psychological components play an important role in the adoption decision (Pan et al., 2015).

The missing elements in the dissemination of new production technologies in the rain fed and irrigated areas are failing to consider the socioeconomic factors for farmers, where the producer skill in receiving and decoding information, farmlevel endowments (land quality and type, building) are felt to be among the important factors influencing the demand for new technology and increasing farm outputs.

Many researchers argue that the adoption of agricultural production technologies in developing countries is influenced by economic and social factors as well as by physical and technical aspect of farming and the risk attitude of farmers. However, because of capital scarcity, especially for small farmers, and risk consideration farmers are rarely in a position to adopt a complete 
recommended technological package (Ogada et al., 2014; Muzari et al., 2012).

\section{METHODOLOGY}

The primary sources of data were the general results of agricultural census 1977, 1997 and 2007 (DOS, 1977; DOS, 1999a ; DOS, 2009). The report of 1997 census was released in 1999, while the report of 2007 agricultural census was released in December 2009. The reports have 45 tables summarizing data on land and livestock holdings according to their size, type and main characteristics at the national level as well as by governorates in Jordan. There is a need for further analysis, interpretation and dissemination of data, in a more user-friendly way, to fully meet the needs of various users. Descriptive statistics using frequency, percentages were used to represent data. The present analysis of agricultural census data is in the form of tables. Use of graphs and charts will be interesting and make it user-friendly. Furthermore, the agricultural censuses provide data related to property rights, socioeconomic factors such as education and source of extension, endowments, technology adoption and fixed assets. More data was collected through the annual agricultural statistics for comparison purposes (DOS, 1997-2007).

\section{RESEARCH PROBLEM}

Agricultural censuses diagnose the changes in agriculture sector over ten years. Thus, the agriculture census is considered a very useful tool to measure the development occurred in different agricultural sectors. In Jordan, agricultural sectors suffer in different directions. One major way is the lack of water used for agricultural purposes. Another is the shift from large farms to small farms due to heritage issues. Moreover, different agricultural activities suffer marketing problems. This research investigates the changes made in agricultural sector over ten years introducing the major issues that require more attention to improve this sector.

\section{RESULTS}

The contribution of the Jordanian agriculture to the country's GDP at current prices increased from JD 110 million in 1997 to JD 147.5 million in 2007. During the same period, the share of agriculture in total GDP decreased from $7.19 \%$ to
$3.6 \%$. In 2007, the agricultural share in GDP at current prices was $3.67 \%$ compared to $8.1 \%$ in 1991. However, the growth rate of agricultural GDP was higher than the growth rate of GDP during the period (1997-2000), whereas there was an annual decline of agricultural GDP by $7.4 \%$ during the period (2001-2007) (DOS, 1997-2008). The declining share of agriculture is a result of structural changes in the Jordanian economy. However, it has to be emphasized that if the agriculture related activities (up-stream and downstream linkages like agribusiness services, inputs and agro-industry) are included, the share in GDP would increase to $29 \%$ (DOS, 2008).

Water is the most limiting factor for agricultural development in Jordan. It is very scarce, and there is an increasing demand for it for non-agricultural purposes. The Jordan Valley Authority (JVA) established an irrigation network system to serve 31,174 ha in the fertile valley on Jordan's western border, an area which makes a significant contribution to the total tonnage of fruit and vegetables produced in Jordan. The annual consumption of irrigation water increased from $470 \mathrm{MCM}$ in 1997 to 591.6 MCM in 2007. However, the highest irrigation water consumption, $72.5 \%$ was over the period 19992007 (Mohsen, 2007). For the agricultural sector the potential for water saving by increasing the efficiency of water utilization and improving the irrigation management are considerable and should be pursued with high priority.

Capital investment is classified into capital investment of private sector and governmental investment in agriculture. Furthermore, within each classification these are divided into investment in building and construction, machinery and equipment and investment in transport facilities. The private sector annual investment increased from 1.7 JD million in 1985 to 3.9 JD million in 2007. The private investment on machinery and equipment also increased from 5.4 JD million in 1985 to 12.8 JD million in 2007 with a maximum of 16.3 JD millions in 1993.

Contrary to private sector investment, most of the governmental investment is concentrated on building and construction. About $80 \%$ of the governmental investment is done by Jordan valley Authority and Ministry of Water and Irrigation in dams construction and irrigation network. 
However, there is a trend to decrease the government investment in agricultural sector. The total government investment decreased from 37.7 JD million in 1997 to reach the minimum of 6.3 JD million in 1991 (DOS, 1999b).

The private capital stock increased from 92 JD million in 1997 to 341 JD million in 2007 with an average growth rate of 8 percent, while the governmental capital stock increased from $245 \mathrm{JD}$ million in 1997 to 534 JD million in 2007 with an annual growth rate of 5.5 percent. The total capital stock in agricultural sector increased from 336 JD million in 1997 to 875 JD million in 2007 with an annual growth rate of 6.6 percent.

\subsection{Growth of Agricultural Labor Force}

The Jordanian labor force increased from 445 thousand in 1997 to 1132 thousand in 2007. Over the same period, agricultural labor increased from 32.8 thousand to 65 thousand. This meant that the contribution of the agricultural sector to employing manpower declined from 7.37 percent to 5.74 percent in the same period. The current agricultural labor market suffers from a shortage of Jordanian labor. Because of the availability of relatively cheap labor from outside, the difficulty of daily mobility of labor to the production regions (mainly Jordan Valley) and the dominance of subsistence agriculture in the rainfed regions, many Jordanian farmers have become more interested in working on a sharecropper basis or leasing their land.

\subsubsection{The number and area of holdings depend mainly on family labor for agricultural operation in Jordan in 1997 and 2007}

Marginal holdings $(<5$ dunums $)$ and smallholdings (5-50 dunums) are becoming more dependent on family labor to perform agricultural operation; whereas the medium (50-500 dunums), large (500-2000) and very large holdings (>2000 dunums) are becoming more dependent on hired labor to perform agricultural tasks. Fig. (1) shows the percentage of area and holdings using family labor to perform the agricultural activities. It clearly shows that as holding size increases the dependence on family labor for agricultural operation decreases. However, the change in the use of family labor in farm operation between two censuses shows that farmers with marginal and small holding are more relying on family labor, whereas medium, large and very large holding are more relying on hired labor to perform agricultural operation (Fig. 1).

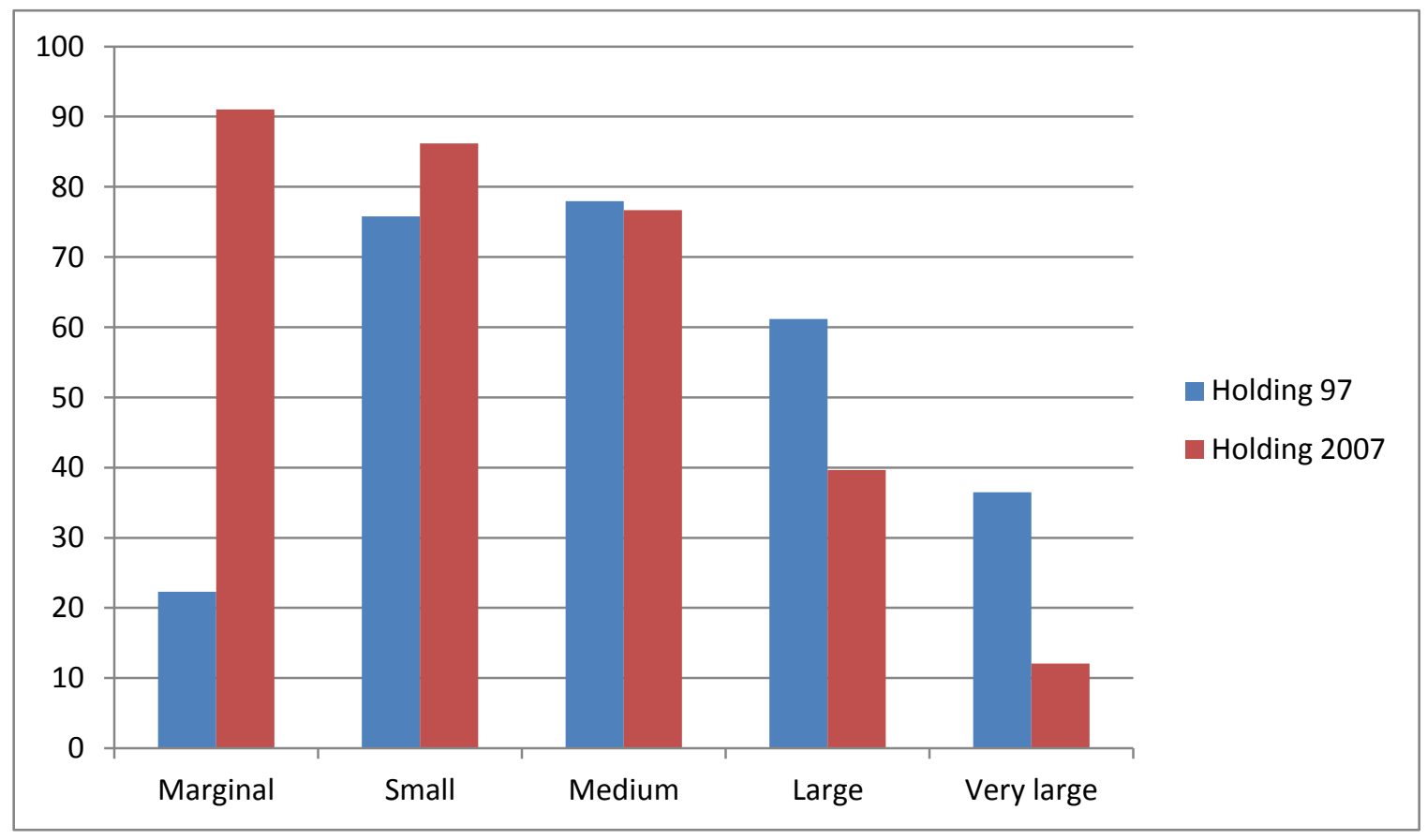

Fig. (1): Percentage of holdings depending mainly on family labor to perform agricultural operation. 


\subsubsection{The number and area of holdings depend mainly on hired labor for agricultural work in Jordan in 1997 and 2007}

Most of small and medium holdings are becoming less dependent on hired labor. Large and very large holding are becoming more dependent on hired labor, Furthermore, $87 \%$ of large holding depends mainly on hired labor to perform agricultural operations (Fig. 2). Smallholdings depend mainly on family labor. As the size of holding class increases, the use of family labor decreases and the use of permanent labor increases. This means that the small size classes contributed more towards solving the unemployment problem of the agricultural labor force. For a policy implication, it is necessary to determine the efficient size of holding in rainfed and irrigated areas that can generate a sufficient income for rural households to be above the poverty line. decreases from West to East and from North to South and, out of a total cultivable area of about 5000 thousand dunums $(5.7 \%$ of the total land area), 4900 thousand dunums (93\%) depend entirely on rainfall to sustain any crop, and only about 739 thousand dunums (14\%) are irrigated. The average cultivated area during the period 1990-1999 was about 2,385 thousand dunums, representing $3.4 \%$ of the total Jordanian area and less than 1 dunum per capita. However, the cultivated area varies considerably from year to year due to changes in rainfall.

\subsection{Growth of Irrigated land}

In the last thirty years more and more areas, especially in the highlands and the Badia region, have come under irrigation. The total irrigated area was 253 thousand dunums in 1990. The irrigated area constantly increased to reach almost 538 thousand dunums in 1997 and 739 thousand dunums in 2007 . Thus, more than $14 \%$ of the total

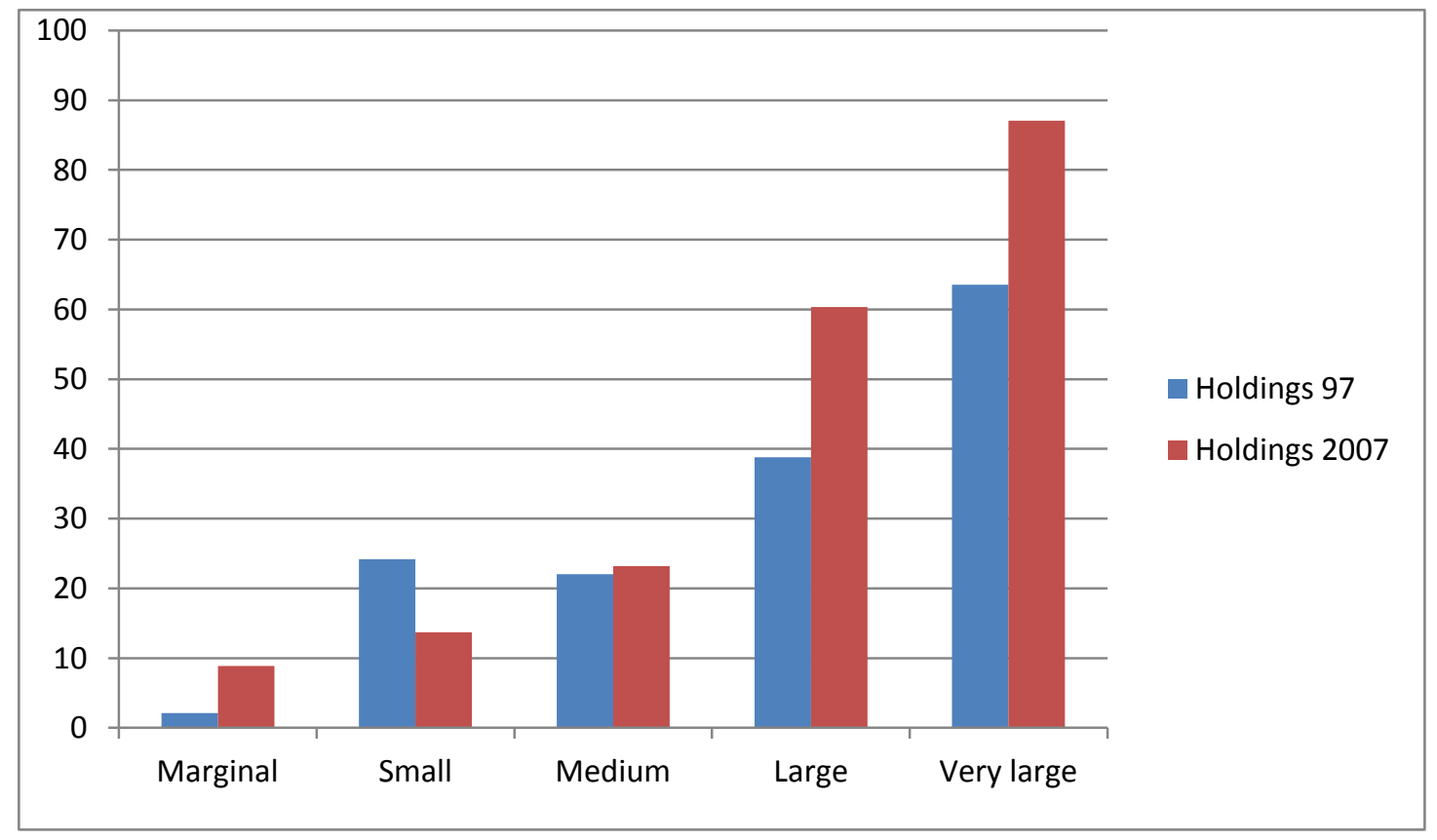

Fig. (2): Percentage of holdings depending mainly on hired labor to perform agricultural operation.

\subsection{Growth of Land Resource}

The total area of Jordan is about 89.2 million dunums, and this land area can be divided into seven climatic zones. In general, since over $86 \%$ of its area is desert which has little economic importance, the whole of Jordan can be classified as a 'low rainfall region. The level of precipitation arable land and about one fourth of the average cultivated area is now under irrigation (Fig. 3).

Due to variations in rainfall, the increase of irrigated area, the shift to cultivating more profitable crops and major changes in the traditional markets for Jordan's agricultural products, the irrigation pattern has changed. The 


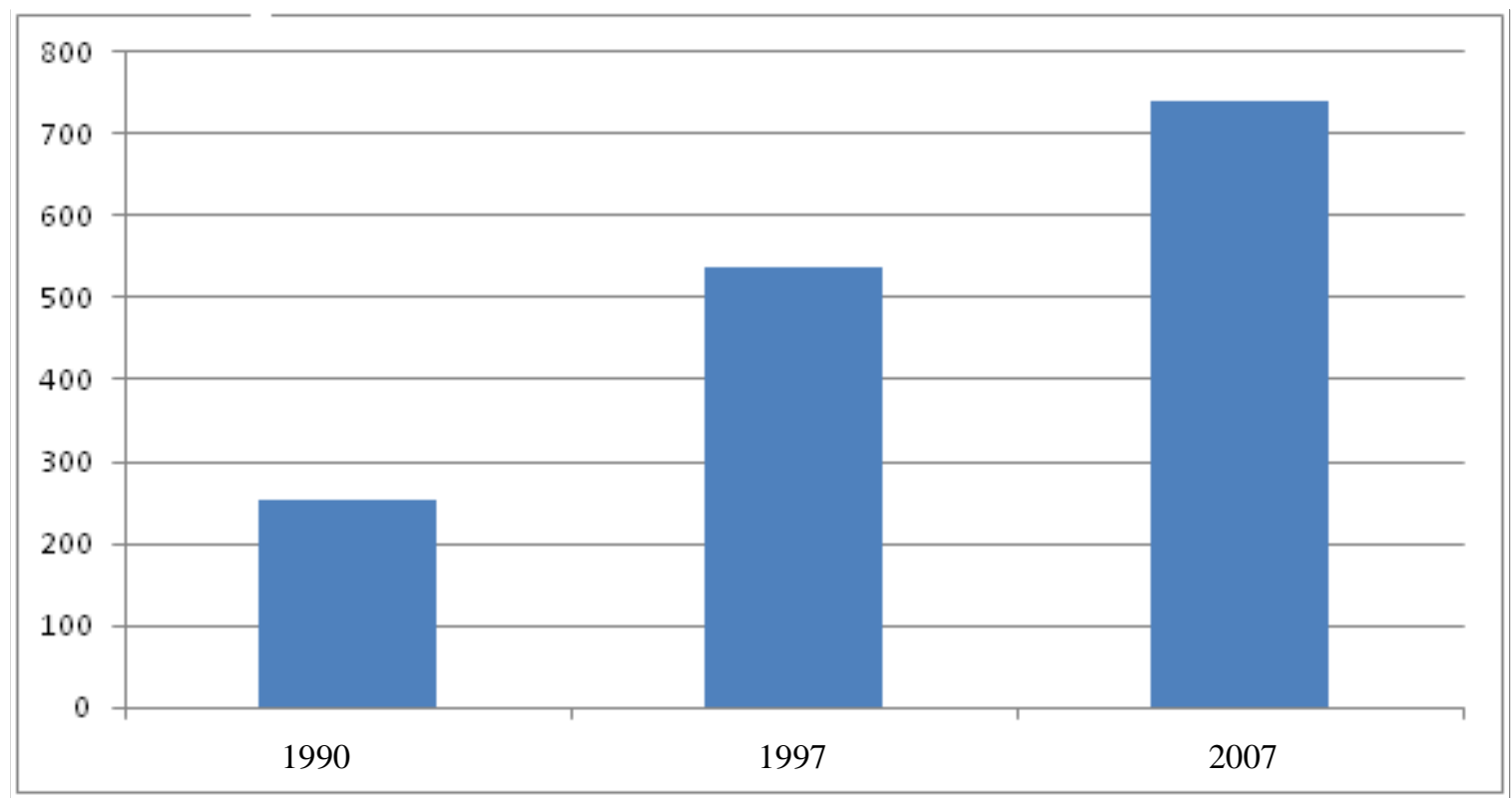

Fig. (3): The increase of total irrigated area from 1990 to 2007.

area of field crops fluctuates sharply from year to year on a decreasing trend. The irrigated field crops increased from $1.7 \%$ in 1997 to $8.2 \%$ of total field crops area. Due to the profitability and comparative advantage of vegetables in Jordan, especially in Jordan Valley, the cultivated area under irrigation has increased with an annual growth rate of 5 percent to reach $92 \%$ of vegetables area. The drastic change in Jordan occurred in fruit production (olive trees). This area increased continuously to reach $44 \%$ of the irrigated areas in Jordan in 2007.

\subsection{Change of Tenure System of Agricultural Land}

Land tenure and size of holdings limit the progress of technology. Farm size, the number of parcels and patterns of ownership are the most important factors in understanding farmers' behavior toward new technologies. Patterns of ownership, leasing, tenancy of land holding, and sharecropping are among the factors that affect farming practice and farmers' decision, particularly decisions to adopt new technologies.

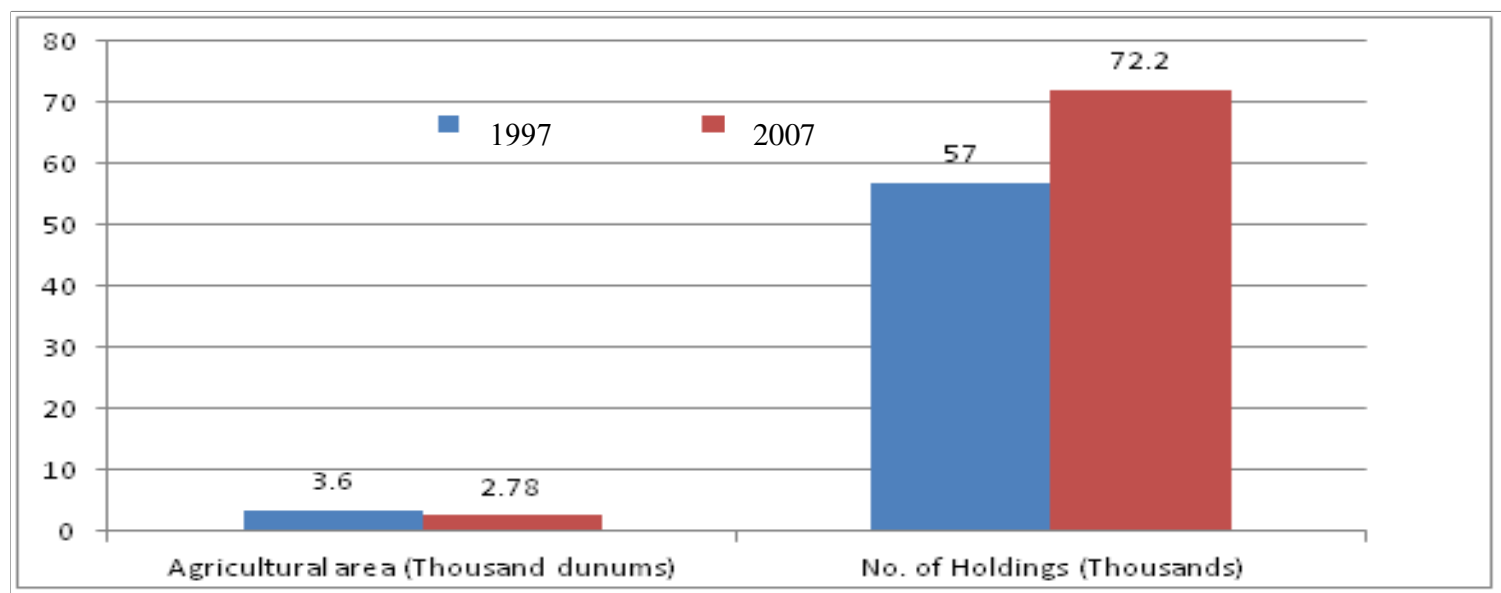

Fig. (4): The changes on agricultural land and the number of holding by 1997 and 2007. 
The total land area has decreased from 3,6 thousand dunums in 1997 to 2,78 thousand dunums in 2007, which can be considered as a negative indicator. This is due to expansion in the urban area at the cost of agricultural area. On the other hand, the number of holdings has been increased from 57 thousand in 1997 to 72.2 thousand in 2007. This reveals the high rate land fragmentation and the reduction in the size of the agricultural holding and the increase in the agricultural holders. Land fragmentation limits the investment and development in the agricultural sector, due to the fact that using of machinery and other fixed assists such as irrigation systems would not be economically feasible in the case of small size holdings (Fig. 4).

Land distribution is highly skewed and land fragmentation is considered to be one of the main causes of low productivity. The 1997 census indicated that $15.8 \%$ of farms had less than 5 dunums, $69 \%$ of farms had less than 50 dunums, only $2 \%$ had between 500 and 5000, and only $0.036 \%$ had over 5000. More than $50 \%$ of holdings are divided into an average of 3.5 fragments. For a farmer who has a holding of 30 dunums and an average of 3.5 fragments, it means that he owns three pieces of land in three different places. Each piece of land consists of about 8.6 dunums. Most of the land is owner-operated and about $16 \%$ of the land holdings are rented. The 2007 census indicated that $28 \%$ of farms had less than 5 dunums, $83 \%$ of farms had less than 50 dunums, only $0.08 \%$ had between 500 and 5000 . Census of 1997 shows that the area classes with a size of lower than 10 dunums represented about $25 \%$ of the total number of holdings in Jordan, while in 2007, the number of holding that belongs to the same area classes increased to about $43 \%$. Urbanization of good agricultural land and speculation have further reduced the cultivated areas. Jordan has a small, but high potential agricultural land resource. Small fragmented farms may avoid or delay mechanization of some farming activities, due to non-rentability of its services. These farms also tend to use labor with less efficiency.

The problem of the fragmentation of holdings has numerous setbacks, which are well known. The small size of plots does not encourage mechanization in rainfed areas, where income per unit area does not justify their incomes from non-agricultural pursuits. Reviewing the distribution of agricultural lands that are economically and environmentally suited to cereal production, it is readily apparent that there is very little potential for the horizontal expansion of cereal production.

The inheritance law for farmland in Jordan has, over the years, led to a severe fragmentation of land and a severe reduction in the size of holdings. The law of land inheritance cannot be altered easily. The small size of plots does not encourage mechanization in the rainfed areas, where income per unit area does not justify hiring mechanized labor. As a result, a farmer in a small village may own several plots of land scattered around various parts of the village, which are time consuming to deal with. Therefore, Jordan is not only faced with natural constraints, but also with other obstacles in the way of agricultural development such as defects in the land tenure system.

Therefore, most holdings in rain fed areas are too small to generate sufficient income. The message to the policy maker here is that factors such as holding size and production technology, which lead to differences in generated income, can be modified by suitable intervention.

\subsection{Growth of Farm Fixed Assets}

Growth in farm fixed assets plays an important role in increasing the agricultural productivity in irrigated and rainfed agriculture. The open-field cultivation of cereals in rainfed areas has largely been mechanized since 1930, when the first tractor was imported. Although tractors are highly versatile, they are mainly used for primary tillage and transport. The use of combine harvesters is spreading very rapidly, due to the many direct advantages that they provide over hand harvesting. It is estimated that about 90 percent of cereal fields are now harvested using them.

The number of tractors in 1997 was 3103 which decreased to 2910 tractors in 2007 which is due to the shrinking of agricultural land. In spite of overall decrease in the number of tractors the number of tractors per unit area is increasing. There is a decline in growth of small and medium holders, whereas there is a positive growth in tractor ownership in large holdings. The results of censuses show that there was a decrease in the number of combine harvesters in Jordan during 1997-2007. The number of combine harvesters in 1997 was 266 which decreased to only 70 in 2007. 
This is explained by the drastic decrease in the area of cereals in the rainfed areas as a result of urbanization and land fragmentation. The number of threshers is decreasing with an annual rate of $22 \%$. This is due to the change of harvesting technology practiced by farmers. Most of cereal farmers are using combine harvesters in marginal areas. Only the cereal farmers in high rainfall areas such as Ajloun are still using this conventional technology, where the land is rocky and mountainous, which is not suitable for mechanization and combine harvesters. The distribution of disk harrow, motors and water pumps according to holding type show a substantial growth in the ownership of these assets. The growth of disk harrow is unrelated to farm size, whereas there is an inverse relation between holding size and the ownership of water pumps. This is due to the fact that most of large and very large holdings are located in the rainfed areas.

\subsection{Technological Change in Jordanian Agriculture}

One of the most important means of accelerating national development in economy is the adaptation and evaluation of new agricultural technology that can be adopted by farmers; this adoption can result in higher incomes for farmers, greater economic efficiency, and growth in the national economy (Johnson and Kellogg, 1984). Adoption of technology has received frequent attention over the years. Sofranko (1984) reported that, agricultural technology is viewed as representing much more than only mechanization. It includes introduction of new farm inputs, such as a new fertilizer, or new plant varieties that are immune to fungus and diseases, and introduction of new techniques or practices, such as new planting and cultivation techniques.

\subsection{Chemical technological change}

The adoption of chemical technology has been faster in irrigated agriculture. All the farmers in

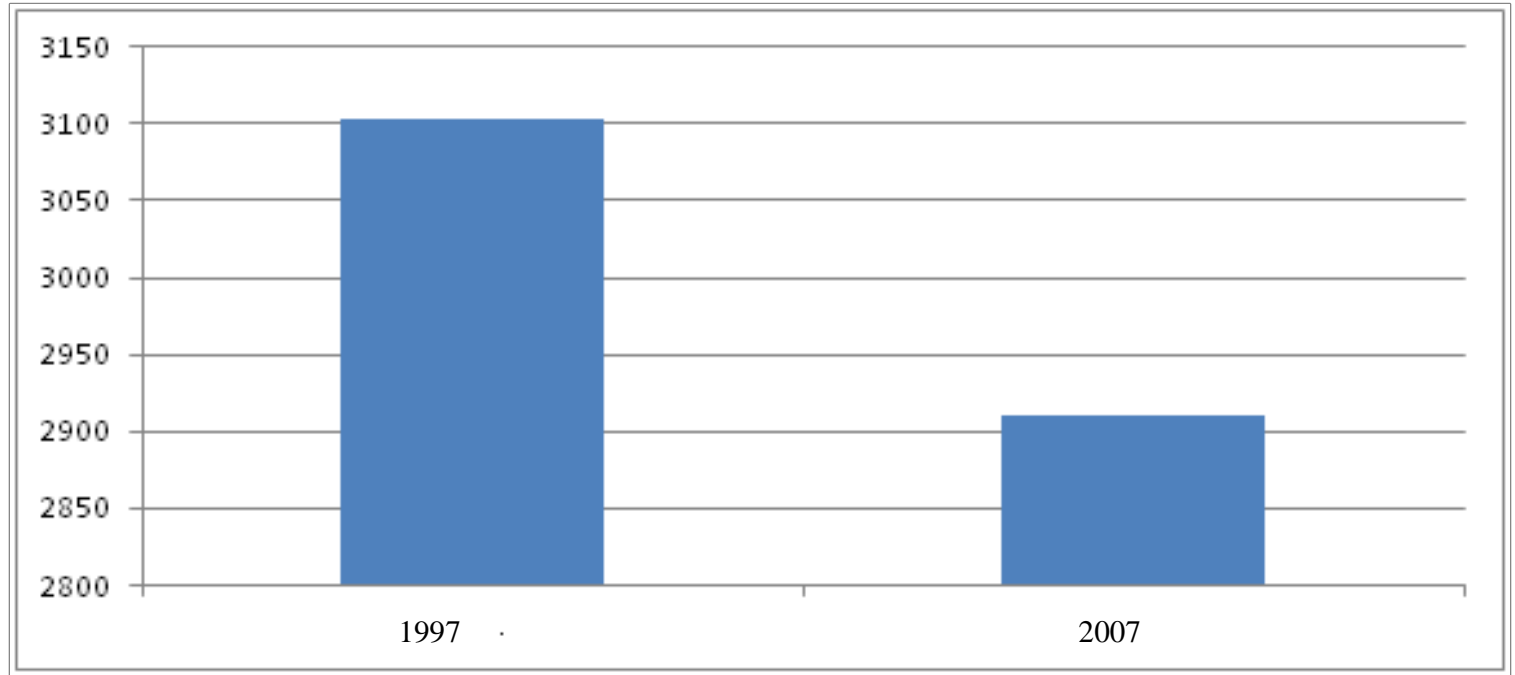

Fig. (5): The change in the number of tractors used in 1997 and 2007.

Concerning the distribution of agricultural machinery according to geographical location in Jordan, most of the agricultural machinery is owned by holders in Northern Jordan. Fig. (3) shows the percentage distribution of agricultural machinery. About $51 \%$ of machinery is located in northern Jordan, $33 \%$ in the middle of Jordan and only $18 \%$ in Southern Jordan. This is due to the facts that most agricultural activities are concentrated in the Northern and Western parts of Jordan (Mafraq, Irbid and Jordan Valley) (Fig. 6). irrigated areas apply fertilizers to vegetables and fruit trees, while in the rain fed area; consumption is still infrequent and low.

\subsubsection{Adoption of pesticides technology}

The intensive use of pesticide has become characteristic of the Jordanian agricultural sector in recent years. The extensive use of herbicides, fungicides and insecticides is considered one of the major problems facing policy makers in Jordan. On one hand, a subsidy and registration policy was made to increase the adoption rate of 


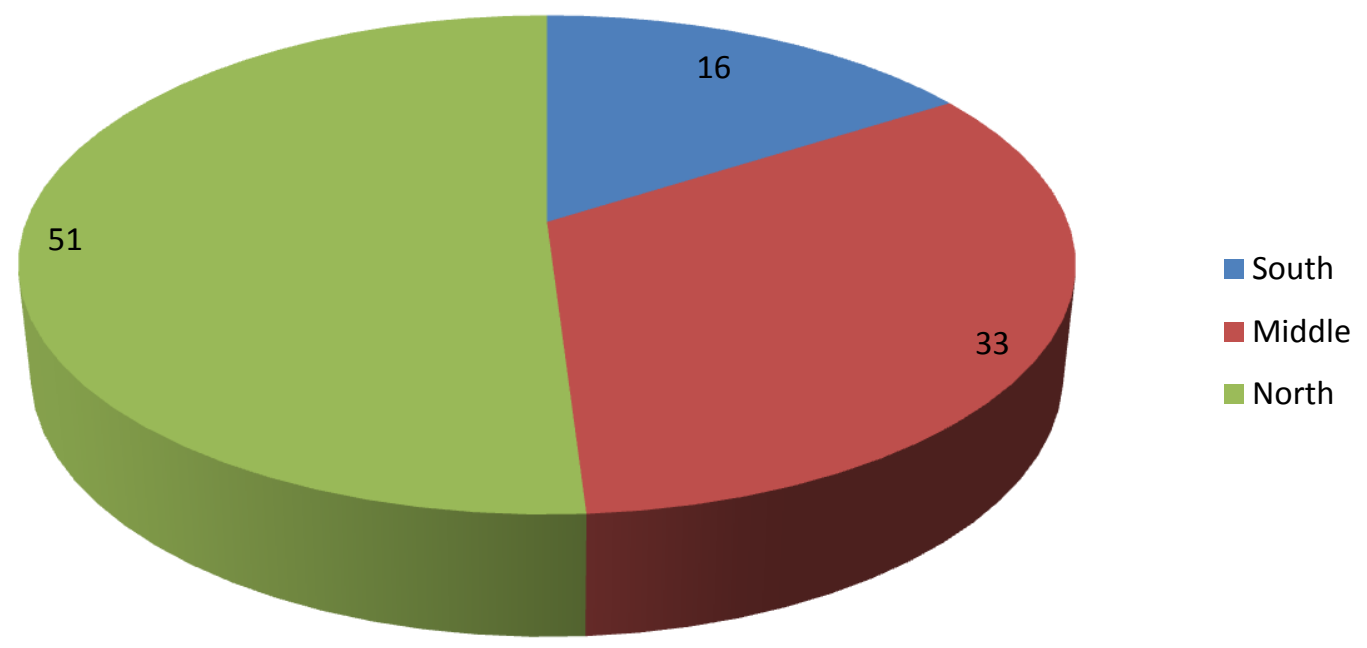

Fig. (6): The percentage distribution of agricultural machinery in Jordan.

pesticides in order to increase agricultural production and reduce yield variation in irrigated areas. On the other hand, the over-utilization of pesticides by the farmers, who try to decrease the damage of the potential yield according to the first order condition for profit maximization.

4.7.2. A comparison between the number of holders adopting pesticides in 1997 and 2007

The results show that higher growth rate of adopting pesticides was by marginal holders $12.3 \%$. Also $22 \%$ of the area held by marginal holders was treated with pesticides. There is no significant difference in the growth rate of adopting pesticides between small and large holders.

\subsubsection{A comparison between the percentages of total holding adopting pesticides in 1997 and 2007}

The results show that $23 \%$ of marginal holding adopting pesticides in 1997 and increased to 58\% in 2007 , whereas $35 \%$ of very large holdings adopting pesticides in 1997 increased to $85 \%$ in 2007. However, in general $27 \%$ of holding in 1997 reported that they were using pesticides, whereas 63\% of holding in 2007 reported that they used pesticides. Therefore, the growth rate of the adoption rate by holders was 7.6 percent annually. In the same manner, in 1997 only $10 \%$ of the area was treated with pesticides, whereas in 2007 75\% was treated with pesticides. Therefore, the annual growth rate of pesticides application of the area was 12.1 percent. It is worth mentioning that increasing the holding size increases the adoption rate of pesticides (Figs. 7\&8). Regional differences in using pesticides indicate that holder in the middle region is more adopting pesticides technology than the holder in north and south. Fig. 6 shows that only $20 \%$ of holders in south are adopting pesticides technology. This is due to the fact that agricultural production in the south is still done by conventional technology and the concentration of agricultural production in Jordan valley and northern highland encourage private sector to promote this technology to these regions.

\subsection{Adoption of fertilizers technology}

The farmers in the irrigated areas show a high degree of appreciation of chemical fertilizer effect on crop yield. Almost 100\% percent of the farmers in the irrigated area are adopting chemical fertilizers. The rainfed farmers show a high degree of appreciation of chemical fertilizer effect on 


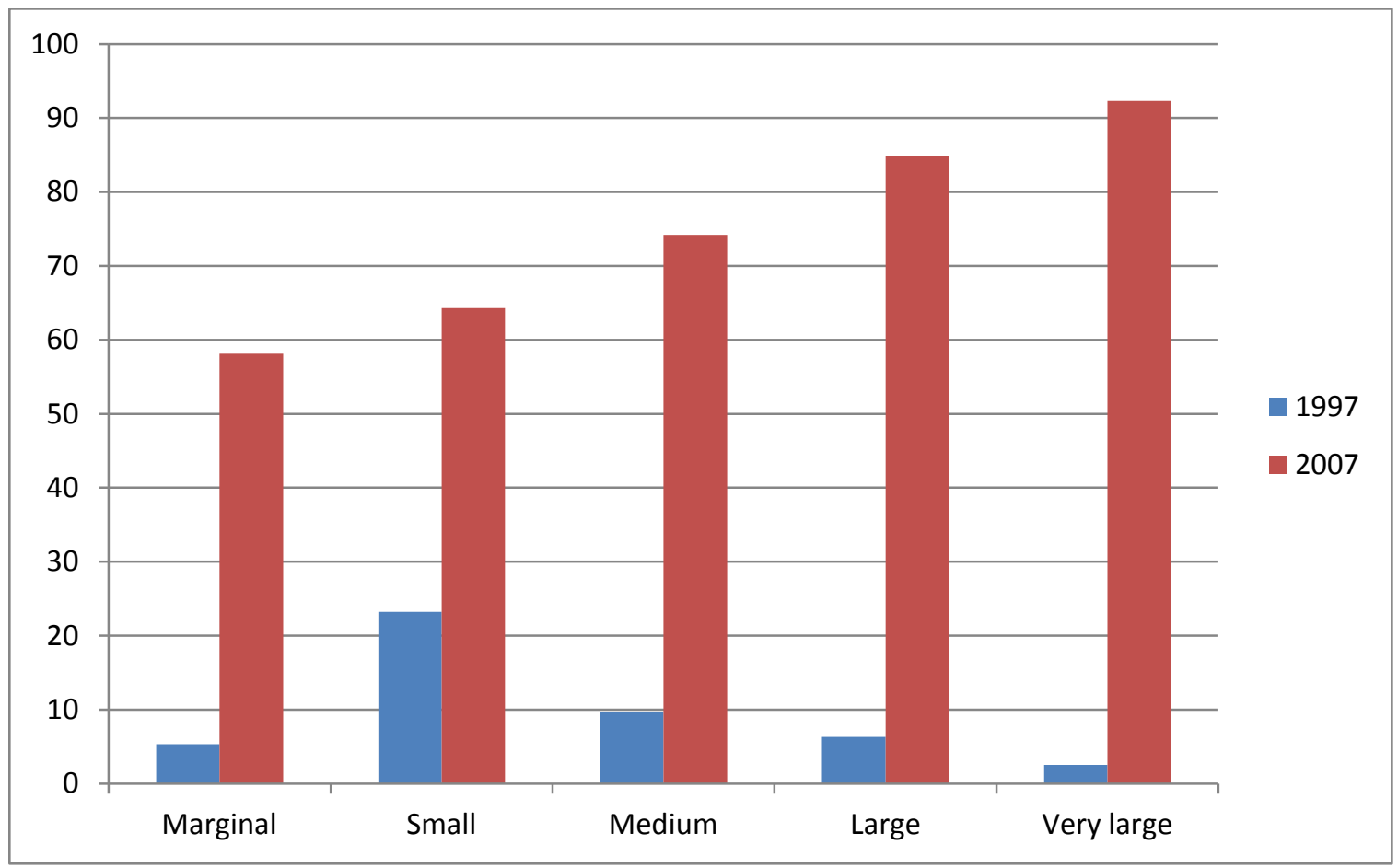

Fig. (7): Total area (thousand dunums) adopting pesticides in 1997 and 2007 by holding classes.

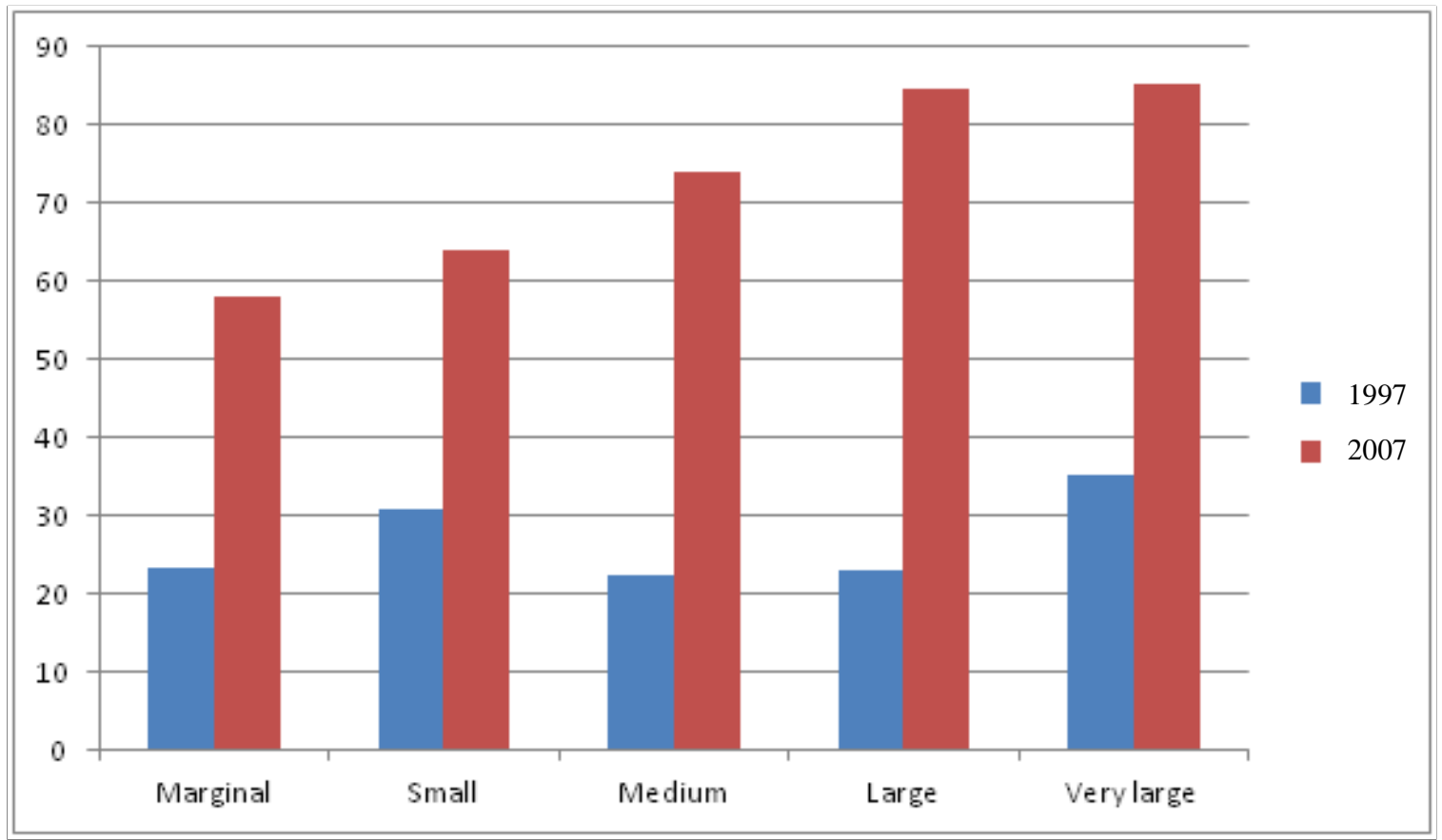

Fig. (8): Number of holdings using pesticides in 1997 and 2007 by holding classes. 
wheat yield. The application of fertilizer is greater in higher rainfall zones than in others, because it requires sufficient rainfall to be effective.

The total number of holders adopting chemical fertilizers increased from 14,233 holders in 1997 to 21,408 holders in 2007 . The growth rate of adoption by marginal holders was $8.6 \%$ compared to the average adoption rate of 2.9 percent. On the other hand, the growth rate of areas treated with chemicals increased annually at the rate of 2.3 percent during the period (1997-2007). entering this market. They are not trying to compete with the private sector, but only to complement its services.

There is an increase of the owner of tractors in marginal, and a decrease in the small holdings. The ownership of tractors in other holding classes remains constant. The increase in the marginal holding, these holders use the tractors to provide custom service to land holders. There is a decrease in the owner of tractors for the smallholding with less than 50 dunums. It is worth to remember that

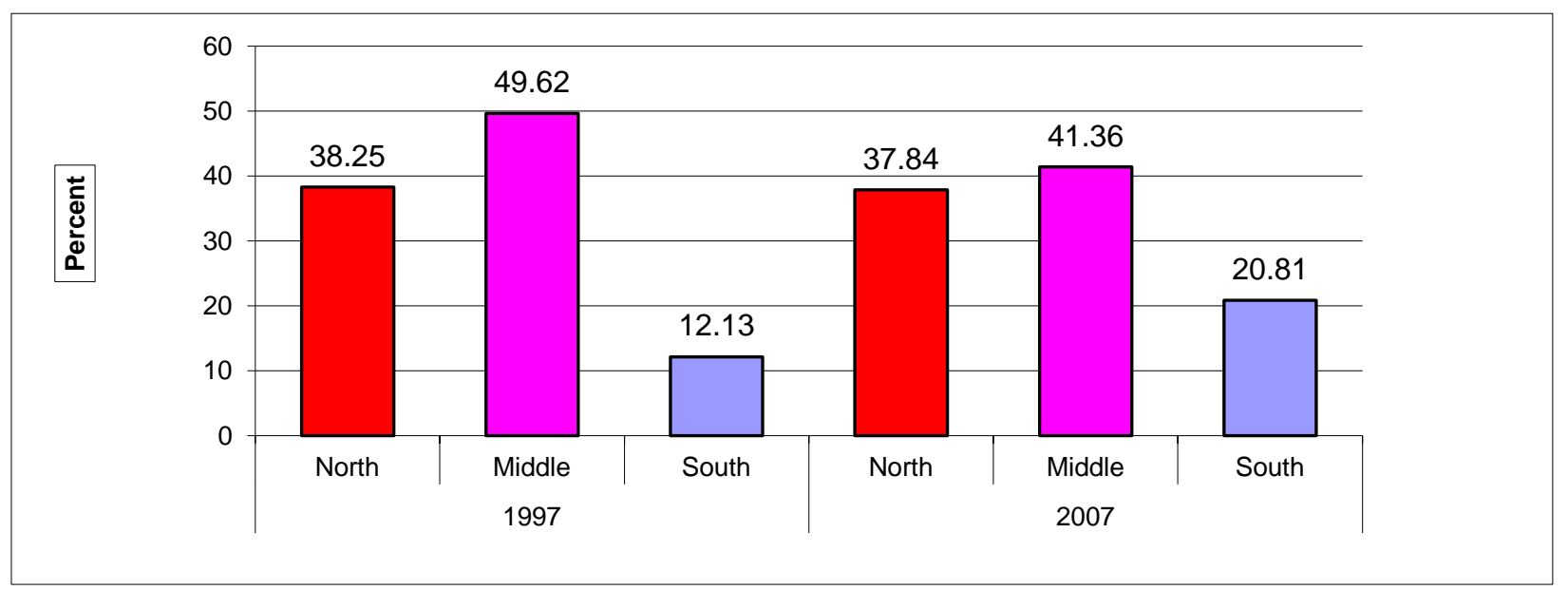

Fig. (9): Holders (\%) who reported using pesticides in North, Middle and South regions of Jordan in 1997 and 2007.

The adoption rate was 25 percent of the total holders in Jordan adopting fertilizers in 1997, whereas this percentage increased to 30 percent of the total holder in Jordan adopting fertilizers. Only 11 percent of the total cultivated area in 1997 was treated with fertilizers, whereas about 42 percent of the total cultivated area in 2007 was treated with fertilizers. The adoption of fertilizers is related to the holding size. As the size of the holding increases the adoption rate and the intensity of the adoption also increases.

\subsection{Mechanical technological change}

Farm machinery and implements are imported to Jordan duty free. However, the spare parts needed for this machinery are not exempt from duty. Locally assembled or manufactured implements are common in Jordan. Because of high capital investment and small land holdings, owning farm machinery may be unprofitable. Custom service operations are available in Jordan through the private sector. However, few government and semi-government agencies are the total area in 1997 census was 3,642 thousand dunums and decreased to 2,786 thousand dunums in 2007. Therefore, in 1997 it was 1,174 dunums per one tractor and in 2007 it was 1,036 dunums per one tractor.

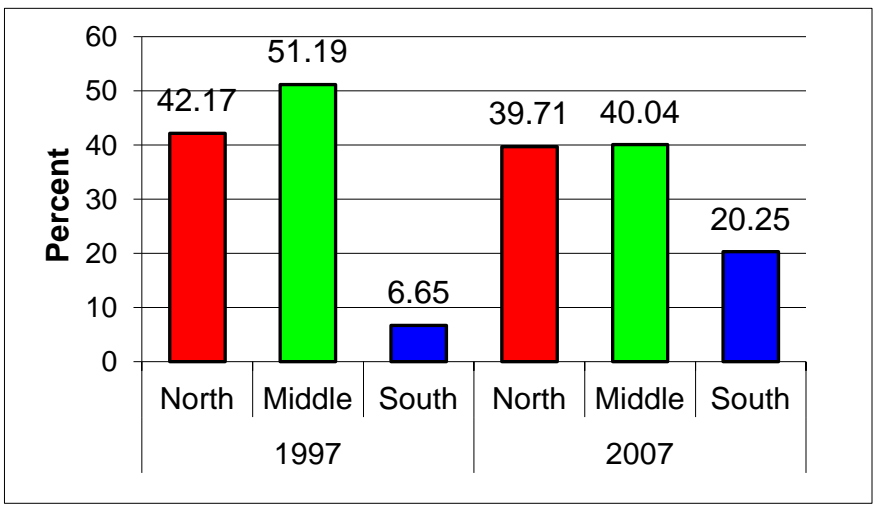

Fig. (10): Percentage of holders adopting chemical fertilizers in North, middle and South of Jordan in 1997 and 2007. 
Moreover, in the small holdings one tractor served about 538 dunums in 1997 and increased for the similar holding size to serve about 852 dunums. It clearly shows that large holdings are more efficient in the utilization of tractors than smallholding. Fig. (8) shows that most of tractors ownership was concentrated in the medium holding regardless of geographical location.

Tillage with draft animals is mostly limited to mountainous regions and small farms. The main reason for using draft animals is the slope of the land, which is not suitable for mechanization. Sometimes the land is suitable for mechanical tillage, but farmers prefer to use animal tillage. Some feel that animal tillage conserves more soil moisture than mechanical tillage.

The use of combines to harvest and thresh cereals is widespread, but limited in some regions as they are not suitable for stony or sloping fields, or because smallholders with livestock prefer to maximize the harvest of straw for feed. In most cases where cereal is hand-harvested, mechanical threshing will follow.

On the other hand, the harvesting and processing of legumes are largely manual, due to a lack of suitable machinery. In a study in the Irbid area, the lentil harvest required just one man-day per dunum. This costs farmers $40 \%$ of their total crop value. In the same study of wheat and barley, the cost of draft animals and manual harvesting is $65 \%$ of the total cost.

\subsubsection{The number and percentage of holders who own the combine harvesters}

The figure is misleading due to the different definition of combine harvesters in the two censuses. The number of harvesters is decreasing from 8,243 combine harvesters in 1997 to 261 combine in 2007, which is unrealistic. It might be that in the 1997 census the threshers were aggregated with combine harvesters. Fig. 12 shows that the ownerships of combine harvester were concentrated in the medium holding. Anyway, Jordan has a shortage of combine harvesters during the harvesting season (June and July) and many of combine harvesters come from Syria to perform custom services for farmers in Irbid region.

The number of owners increased from 124 in 1997 to 2,329 in 2007 with an average growth rate of 21 percent. The plower could be manufactured locally and there is a high correlation between the number of tractors and plowers, which is independent of holding size.

The number of owners of mechanical motors increased from 795 in 1997 to 1,649 in 2007 with an average growth rate of 5.2 percent. Adopting mechanical motors seems to be independent of holding size. The number of pump owners increased from 742 in 1997 to 2,758 in 2007. This is reflected by the increase in the area under irrigation. The area under irrigation increased from 275 thousand dunums in 1997 to 739 thousand

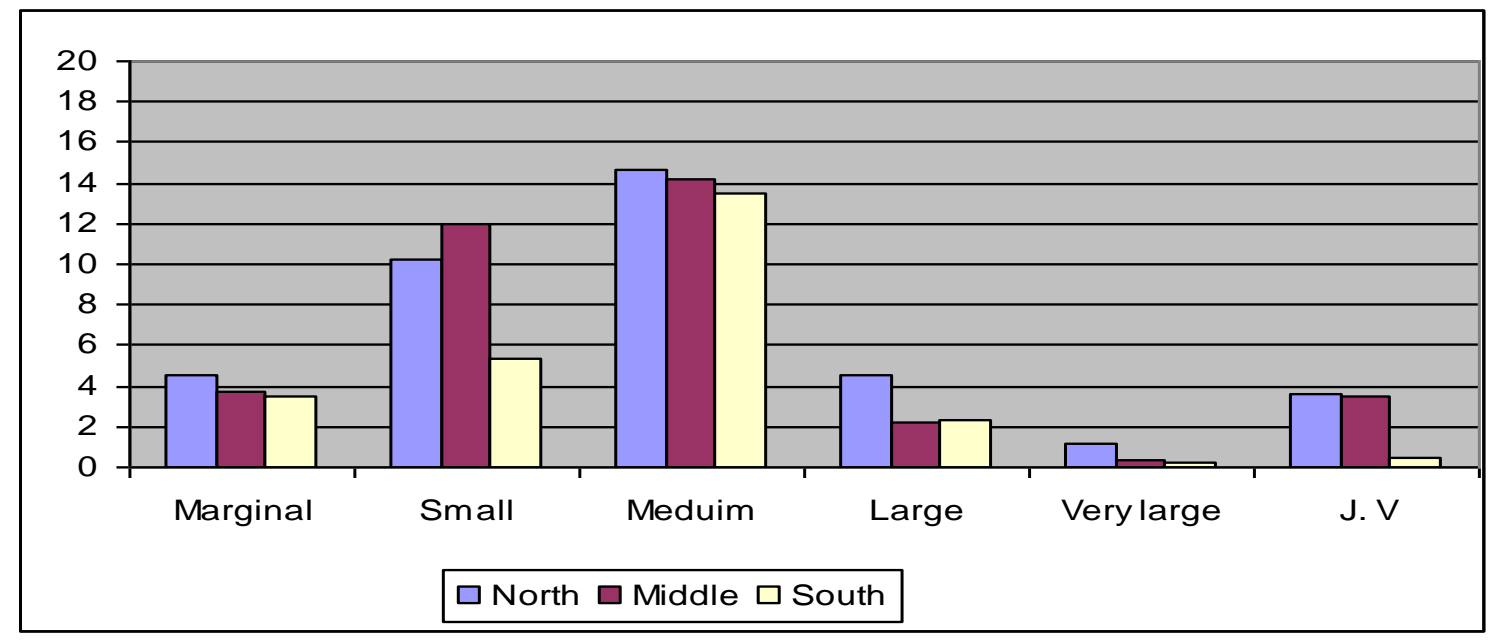

Fig. (11): Percentage of holders who own tractors in North, middle and South of Jordan. 
dunums in 2007 with an average annual growth rate of 7 percent. The owners of pumps increased with an annual growth rate of 9.4 percent. Therefore, it may be concluded that adoption of irrigation pumps is highly correlated with the increase in the irrigated area

In Jordan, capital is invested in rainfed agriculture in the form of machinery such as tractors, combines, sprayers and other small equipments. This has been very low compared to what has been invested in the irrigated areas.

\subsection{Biological technological change}

The farmers' acceptance of the new varieties is conditioned by the extent of the difference in their productivity and palatability and those of the old familiar varieties. New varieties have been widely adopted by producers, irrespective of farm size and tenurial status. The results indicate that 15.8 percent of the holdings in 1997 adopted new seed varieties on 17.5 percent of the area, whereas in 2007, 21 percent of the holdings used new seed varieties in 44 percent of the areas. Thus the growth rate of adoption of the new varieties was 3.7 percent annually. Small farms were more responsive to new varieties than large farms.

The adoption rate in the middle region was twice the adoption rate in the southern region. Fig. (10) shows the percentage of farmers adopting new seed varieties according to the geographical location. It shows that the adoption rate in the southern region increased from 10.7 in 1997 to $26 \%$ in 2007. However, most area under irrigation was planted with new seed varieties of vegetables, fruit trees and banana. The old varieties of these crops almost disappeared. The decreasing cost of production per one ton due to this technological change will not allow the traditional farmers who still use old varieties to survive in the market. If the new variety is superior to the old variety at high levels of input use, various input-output price policies might be considered to encourage adoption rate. Seeds represent a very important input for high yields.

The private sector plays an important role in the diffusion of new seed varieties of vegetables and fruit trees. These new varieties are a kind of private goods and cannot be multiplied by farmers. The farmers should purchases these new seed varieties from the private sector.

\subsection{Introducing new input to traditional technology}

Use of organic fertilizers is considered an important technological change by adding additional input to the production factors. Application of organic fertilizers to the soil is a well-known practice used by farmers in rainfed

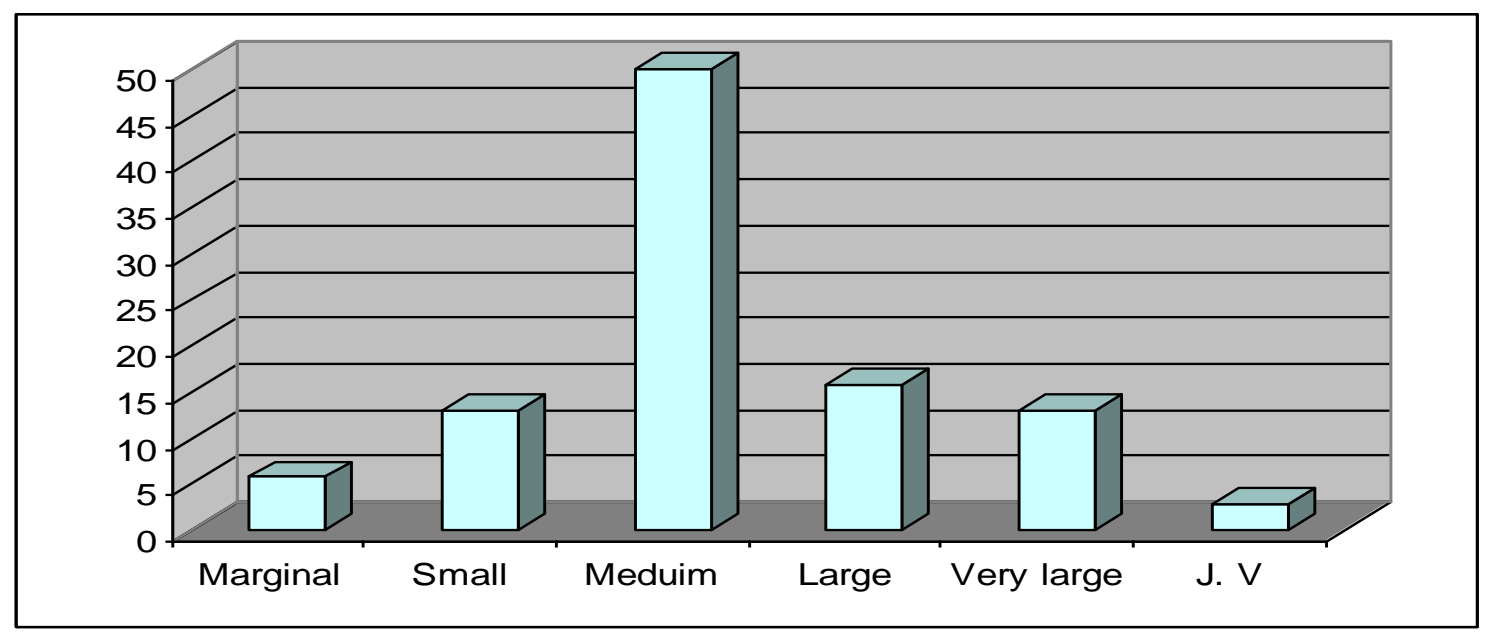

Fig. (12): Percentage of holders who own combine in North, middle and South of Jordan. 
and irrigated areas. However, using unfermented organic fertilizers is considered a problem in the Jordan Valley. High moisture and temperature in Jordan Valley in addition to unfermented organic fertilizers are considered favourable environments for housefly. During summer housefly is one of the environmental problems in Jordan Valley. Therefore, there is a governmental regulation to prevent transfer of unfermented organic fertilizers from highland to Jordan Valley. The results of the agricultural census show that the number of holdings using organic fertilizers increased from 10 percent in 1997 to about 52 percent in 2007. The price of fermented organic fertilizers is higher than the price of unfermented organic fertilizers and therefore many farmers still use unfermented organic fertilizers. However, the use of organic fertilizers was not correlated with the holding. However, the use of organic fertilizers in very large holdings was more than in other holding size classes.

Only 13 percent of the holders in the southern region were using organic fertilizers in their holding compared to 50 percent in middle and 38 percent in northern region. It could be explained by the scarcity of organic matter and poultry and dairy farms in the southern region compared with the northern and middle regions.

\subsection{Change of production technologies in Jordan}

Farmers in Jordan Valley in response to the increase in the scarcity of water available for irrigation, distortions between supply and market demand of perishable vegetables and low productivity due to major environmental stress factors; evolved production methods to overcome the negative impact of these developments. Methods of irrigation, for example, have been changed from the traditional furrow irrigation to the introduction of the more efficient drip irrigation systems. The change to the new irrigation method has been faster in vegetable cultivation than in fruit tree growing. In 1994, drip irrigation method covered 85 percent of the area cropped with vegetables compared with only 11 percent of the area planted with fruit trees.

Although the change is significant, it only covered 25 percent of the water used for irrigation of which the share for vegetables was 19 percent compared with 9 percent for fruit trees. The share of fruit trees of water consumed in the JV in other words was twice that of vegetables in 1994. The efficiency with which the irrigation system has been used has been reported to be lower than expected. Both the technology used and irrigation schedule require refinement to raise the efficiency of water use from its overall present level of 70 percent to 80 percent or more.

The second change adopted by the farmers was the introduction of plastic tunnels and mulch culture, plastic house culture, and the fast and efficient method of off-season seedling production and transplanting (seedling). All these methods modify the environment in order to spread the seasons of vegetable production and consequently have better control on spacing of vegetable harvesting dates to be consistent with market demand. The ultimate goal is to avoid oversupply in certain weeks or months and strive to achieve more rewarding prices.

About 92 percent of vegetables produced in Jordan were irrigated and only $8 \%$ were produced in rainfed areas. Summer vegetables such as onion, snake cucumber, peas, and okra are mostly cultivated in rotation with wheat and legumes. The main vegetables such as tomato, potato and eggplant are wholly produced in irrigated areas. However, the area of vegetables under drip irrigation represented 77 percent of the total irrigated area under vegetables. Irrigation in open field represents 64 percent of the irrigation technology. Sprinkler irrigation represent 7.3 percent. Production of vegetables under plastic houses is practiced in about 4 percent of the irrigated areas.

In order to achieve the objective of efficient and sustainable utilization of Jordan's available production resources, policies and strategies should be adapted to maximize the efficiency of water storage, conveyance, distribution and onfarm application.

\subsection{Development of agricultural production in Jordan}

Increasing the total agricultural output can be realized by the following three methods as indicated by Norton (1988):

- Increasing the agricultural areas by bringing the unused, but potentially productive lands under cultivation.

- Increasing cropping intensity.

- Increasing the productivity of inputs. 
Agricultural production in the predominantly rainfed areas of the country is a high risk undertaking due to erratic rainfall, frost damage and shortage of inputs. The crop production varied widely from one year to another. The variation was due to changes in planted area as well as productivity of the cultivated land each year. The average production of the three major groups of crops averaged 1.1 million tons per year, equivalent to 37 percent of the total agricultural income for the period 1997-2007.

\subsubsection{Development of field crops production in Jordan}

The area of field crops decreased by 3.5 percent annually during the period 1990-1997 and then increased by 0.35 percent during the period 1991-2007 The production of field crops increased on an average by 9.5 percent annually during the first period and decreased by 0.43 percent during the second period. This was due to the leasing of the southern desert region to commercial companies by the government. They used highly mechanized technology with a central pivots irrigation system to increase wheat production under irrigation.

\subsubsection{Development of vegetables production in Jordan}

The vegetables are decreased by 4 percent annually during the first period and then increased at the rate of 2.3 percent; the total vegetable production increased by 3.5 percent annually during the period (1997-2007). This was due to the substitution of vegetables with fruit trees in the first period as the price of fruits increased and there were marketing bottleneck in vegetables due to export difficulties. At the same time, productivity of vegetables improved and supply of a large number of vegetables was in excess of domestic demand as well as of the export markets. During 1997-1988 supply of certain vegetables like tomatoes, eggplants, cucumber and squash was higher than their demand while the domestic demand for some vegetables like potatoes and onions was much higher than supply. The vegetable area increased gradually to reach 495 thousand dunums equivalent to an increase of 45 percent in the base year of 1997.

The main reason behind the increase in the area of vegetables was the increase in water supply for these crops in the highland areas and in the Jordan Valley.

\subsubsection{Development of fruit tress production in Jordan}

The area of fruits increased from 425 thousand dunums in 1997 to 831 thousand dunums in 2007 or at the rate of 4 percent annually whereas their production increased from 128 thousand tones to 320 thousand tonnes, annual growth rate of 6.2 percent for the same period. The expansion of fruit production in Jordan was mainly due to the extension of irrigation (particularly in the Jordan Valley) and the introduction of improved agricultural technology.

\subsubsection{Horizontal expansion in Jordanian agriculture}

There is a limited potential to bring hitherto unused, but potentially productive land under cultivation in Jordan. The increasing population has already used a large part of the land suitable for agriculture in the various agro-ecological regions. Large scale expansion of marginal land with low productivity, and with fluctuating production is very critical from an economic and ecological point of view.

The irrigated area increased from 490 thousand dunums during 1990-1997 to 699 thousand dunums during 2001-2007 with an annual average growth rate of 5.9 percent for the first period and 2.3 percent in the next period, respectively. On the other hand, the total cultivated area under rainfed conditions increased from 1,678 thousand dunums in the first period to 1,770 thousand dunums in the next period. There was a negative growth rate for the period (1997-1990) at an average of 3.4 percent. However, the rainfed cultivated area increased at the rate of 2.3 percent for the period (2001-2007). In conclusion, there is a horizontal expansion of cultivated area in Jordan during the period (1997-2007). The total cultivated area increased from 2,167 thousand dunums to 2,469 thousand dunums during the periods (1997-2000) and (2001-2007), respectively. Furthermore, there has been an increase in the percentage share of irrigated areas in Jordan, it increased from 23 percent for the period (1997-2000) to 28 percent for the period (2001-2007). During the first period the percentage of the irrigated area increased by 7.88 percent annually due to the huge investment in irrigation and exploring new water resources.

\subsubsection{Vertical expansion in Jordanian agriculture}


For vertical expansion of crop production there are two possibilities, the first is to increase crop intensity, and the second is to increase the productivity of agricultural inputs by adopting new technologies, training, and agricultural extension.

\subsubsection{Increasing cropping intensity}

Vertical expansion by increasing cropping intensity is a relevant alternative in order to increase agricultural production. Option of increasing cropping intensity was only available in Jordan Valley for the period 1988-2000. Therefore, cropping intensity in highlands will not be discussed. However, the irrigable area in Jordan Valley is about 364 thousand dunums. The total irrigable area in Safi Ghor is about 77 thousand dunums. The actual irrigated area in Jordan valley was on an average 222 thousand dunums for the period (2006-2007). The area actually irrigated in Safi Ghor is about 47 thousand dunums.

The overall cropping intensity in the JV fluctuated slightly from one year to another during the period 2002-2007 with the exception of 1992, when the cropping intensity reached 134 percent due to the exceptional rainfall in that year. During 2002-2007 the overall cropping intensity for the four zones ranged from a high of 134 percent in 1992 to a low of 117 percent in 1994. However, the fluctuation in the area cropped each year by zone was much higher than the overall average. Cropping intensity in the North, for example, fluctuated the least among the zones and ranged from 111 percent to 122 percent during the period 200-2007. The fluctuation in the area cropped in southern JV, on the other hand, was the highest among the zones and ranged from a high of 110 percent in 1990 to a low of 85 percent in 1994 . The main cause in the variation of cropping intensity was the level of sufficiency of water supply in each region. Water resources in the North region are conveyed to middle and southern regions through KAC but only when farmers take their share of water. Water resources originate in the Northern region.

\subsubsection{Increasing productivity in Jordanian agriculture}

Considering the limited agricultural resources in Jordan and the constraints in rehabilitating new land for cultivation, increasing production by raising the productivity is one of the most important options. This alternative should be given priority, since a large potential to achieve considerable increases in the average yields exists.

\subsubsection{Development of field crops productivity}

One of the objectives in the third five-year development plan (1986-1990) was to increase agricultural productivity as one of the tools to promote continuous growth in the agricultural sector. The average yield of field crops increased from $83 \mathrm{~kg} /$ dunum for the period (1997-2000) to $94 \mathrm{~kg} / \mathrm{dunum}$ for the period (2001-2007).

\subsubsection{Development of vegetables productivity}

The productivity of vegetables improved and the supply of a large number of vegetables was in excess of domestic demand as well as of the available export markets. It became clear during 1997-2000 that the supply of certain vegetables like tomatoes, eggplants, cucumber and squash was higher than their demand while the domestic demand for some vegetables like potatoes and onions was much higher than supply. Productivity levels of over supplied vegetables were much higher than the under-supplied ones, a factor that made farmers to decide and to risk planting these crops in large areas while expecting higher incomes. The main reason behind the increase of productivity in vegetables was the adoption of plastic houses, new irrigation technology, high yielding varieties and the adoption of chemical fertilizers and pesticides.

Despite a decrease in the area under main vegetables in Jordan during the period 1998-2007 at 0.34 percent, both its production and productivity increased significantly at the rate of 3.48 and 3.82 percent per annum, respectively. All vegetable crops showed a significant increase in productivity. Cucumber and watermelons showed a high growth rate in productivity during the last period. The yield of cucumber increased from 2.53 tonnes /du during 1984-1986 to 8.60 tonnes /du during 1995-1996. The main reasons for the increase being the adoption of plastic houses, fertilizers, new seed varieties. At present cucumber is planted completely in plastic houses. The average yield of vegetables increased from $2,144 \mathrm{~kg}$ dunum during 1997-2000 to an average of 2,684 kg/dunum during 2001-2007.

\subsection{Development of fruit trees productivity}

The expansion of Jordan's production of fruits was mainly due to the extension of irrigation (mainly in the Jordan Valley) and the introduction of improved agricultural technology. The fruit 
trees area increased on an average by 4 percent annually, whereas the production of fruits increased by 6.22 percent annually.

Therefore, the productivity of fruits increased by over 2 percent annually. For, example, the yield of one dunum of lemons increased from 1,597 $\mathrm{kg}$ /dunum in 1986 to $2,059 \mathrm{~kg}$ /dunum in 2007 with an annual growth rate of 2.5 percent. The average yield of fruits increased from $452 \mathrm{~kg}$ /dunum for the period (1997-2000) to an average of $529 \mathrm{~kg} /$ dunum for the period (2001-2007).

\section{DISCUSSION}

Deep analysis of the agricultural sector in ten years gives some serious warnings. The performance of the agricultural sector retarded in ten years concerning its share in GDP. This sign is considered the first that should be considered which gives negative sign for this sector and the others in directly. Despite the growth made in agricultural sector, but it that seems the investments and growth in other sectors are more in producing more share in GDP and decreased the agricultural sector share.

Agriculture sector suffers of labor shortages. Most of foreign labor is interested in sectors other than the agricultural sector. The governmental policies did not succeed to solve this gap. Moreover, the foreign labor which is registered to work in agricultural sector do not practice that in reality. On the other hand, the segmentation of large size holdings decreases the demand on external labor and replaces it with family work. Most of labor is used in large size holdings.

The cultivated area fluctuating over years depending on rainfall and the availability of water for irrigation specially in Jordan valley area. The areas with less available water for irrigation tend to depend on trees such as olive as a planting pattern. In irrigated areas the pattern is dominated by vegetables more than other crops.

The use of machinery has decreased from 1997 to 2007 dramatically. The causes of this decrease may result in the change of planting pattern in different areas. Moreover, the use of technology has been changed over years. The trends showed that the use of pesticides increased as a source of biological control. This behavior affects health and environment negatively. The wide use of chemical pesticides will increase the overburden for farmers and decrease safety of vegetables for consumption.
Such behavior will decrease the demand on Jordanian cops abroad. The excessive use of pesticides may have an effect on society welfare and human health, and sometimes lead to diverse economic and ecological effects. This has been shown by a boycott of Jordanian vegetables by the import countries due to the belief that the exported commodities have high pesticide residue. In fact the chemical analysis of pesticides residue shows that Jordanian vegetables do not exceed the international limits of pesticides residue.

The most dominant change in technology with positive impact was the use of water save tools. The dominant irrigation system was the drip irrigation which helps in save a lot of quantities of water. Most of drip irrigation system is used for vegetable crops specially in Jordan valley.

\section{Recommendations}

According to the previous results and discussions the following can be recommended:

1. The governmental policies should be directed to support the agricultural sector and these policies should consider sustainability.

2. The government should formulate policies to minimize land segmentation to enrich the agriculture business more than family business.

3. The economics of production in agriculture should consider the minimization of using pesticides and herbicides to decrease expenses and minimize the environmental effect.

4. Despite the distribution of using economic irrigations systems, care should be given for these systems to keep them efficient in reserving water.

5. Agricultural patterns should be considered part of the governmental policies to solve different problems related to irrigation, marketing and crop balance.

\section{REFERENCE}

Byerlee D., Diao X. and Jackson C. (2005). Agriculture, rural development, and propoor growth: Country experience in the post-reform Era. Agriculture and Rural Development Discussion Paper 21. World Bank.

Byerlee D., Janvry A. and Sadoulet E. (2008). Agriculture for development: Toward a new paradigm. World Bank Report.

Dethier J. and Effenberger A. (2011). Agriculture and Development: A brief review of the 
literature. World Bank Policy. Research Working Paper No. 5553.

DOS (1977). General results of the agricultural census (1975). Department of Statistics, Amman- Jordan.

DOS (1997-2007). Annual agricultural statistics. Department of Statistics, Amman- Jordan.

DOS (1999 a). General results of the agricultural census 1997. Department of Statistics, Amman- Jordan.

DOS (1999 b). Annual agricultural statistics 1998. Department of Statistics, Amman- Jordan.

DOS (2008). National Accounts 1997-2007. Department of Statistics, Amman, Jordan

DOS (2009). General results of the agricultural census 2007. Department of Statistics, Amman- Jordan.

Johnson S. H. and Kellogg E. D. (1984). Extension's role in adapting and evaluating new technology for farmers. In: Swanson,B. E. Agricultural extension, $2^{\text {nd }}$ edition, Food and Agriculture Organization of the United Nations, Rome, pp.40-55.

Mohsen M. (2007). Water strategies and potential of desalination in Jordan. Desalination. Pp.: 27-46.

Muzari W., Gatsi W. and Muvhuzi S. (2012). The Impacts of technology adoption on smallholder agricultural productivity in Sub-
Saharan Africa: A Review. J. Sustainable. Develop. Vol. 5(8): 69-77.

Norton R. D. (1988). "Policy analysis for food and agricultural development -basic series and their uses-." Report prepared for the office of international cooperation and development. USDA.

Ogada M., Mwabu G. and Muchai D. (2014). Farm technology adoption in Kenya: a simultaneous estimation of inorganic fertilizer and improved maize variety adoption decisions. Agric. and Food Econ. Vol. 2:12-20.

Pan Y., Smith S., and Sulaiman M. (2015). Agricultural extension and technology adoption for food security: Evidence from Uganda. Discussion paper no. 9206.

Pinstrup-Andersen P. and Shimokawa S. (2006). Rural infrastructure and agricultural development. Annual Bank Conference on Development Economics, Tokyo, Japan.

Sofranko A. J. (1984). Introducing technological change. In: Swanson, B. E. Agricultural extension, 2nd edition, Food and Agriculture Organization of the United Nations, Rome, pp. 21-39. 


$$
\begin{aligned}
& \text { تأثير نمو الموجودات الثابتة وتبني التكنولوجيا في الإتــاج الزراعي } \\
& \text { جواد عاطف الضلاعين } \\
& \text { قسم العلوم التربوية والاجتماعية ـ كلية الكرك الجامعية ـ جامعة البلقاء التطبيقية ـ الأردن }
\end{aligned}
$$

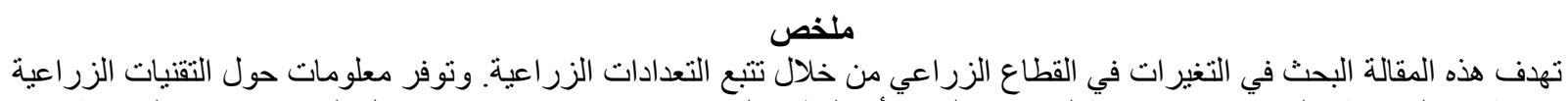

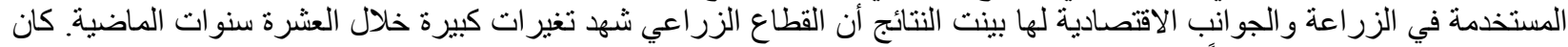
غياب الاستر اتيجية الوطنية سبياً في التغير الات التئة الكثيرة.

المجلة العلمية لكلية الزراعة التية - جامعة القاهرة - المجلد (67) العدد الثاني (أبريل 2016): 123-140. 